\title{
LGBT DALAM PERSPEKTIF HUKUM ISLAM
}

\author{
Hasan Zaini \\ Fakultas Ushuluddin Adab dan Dakwah IAIN Batusangkar \\ J1. Jenderal Sudirman No. 137, Lima Kaum Batusangkar \\ e-mail: hasan.zaini@yahoo.co.id
}

\begin{abstract}
Issues concerning with LGBT seem to be never lasting discussions. These are due to several disciplines, such as health, psychology, Islamic law, other related ones, that may give significant affects in the process making decisions concerning with the issues. Among the issues are dealing with positioning of LGBT either as nature or nurture, given or socially constructed, inherited or deviant, normal or diseased, and so forth. Such abnormal behaviors lead this group to the false understanding about sex in the wrong ways. This points out that the people that gets involved in LGBT fail to synchronize their desire and principles of life. This paper, therefore, aims at analyzing the perspectives of Islamic scholars of Islamic jurisprudence (fiqh) concerning with LGBT and the effects as well caused by.
\end{abstract}

Kata kunci: LGBT, homoseksualitas, al-sahaq, heteroseksual, biseksual

\section{PENDAHULUAN}

$S$ eks adalah salah satu potensi terbesar $S$ yang diberikan Tuhan kepada manusia. Potensi itulah yang dapat menjadikan manusia dapat berhubungan seks dan melahirkan keturunan. Dengan potensi seks tersebut kelestarian hidup manusia terjaga. Secanggih apa pun teknologi perkembangbiakan diciptakan tidak akan dapat mengalahkan proses reproduksi manusia secara alamiah melalui hubungan seks yang normal antara pria dan wanita. Seluruh agama telah menetapkan ketentuan pernikahan yang sah agar sakralitas hubungan seks terjamin legalitasnya (Anang Harris Himawan, 2007: 67). Allah Swt telah melarang seluruh perilaku yang menyimpang karena menyimpan beberapa hikmah yang apabila direnungkan sangat banyak manfaatnya bagi manusia. Namun, sikap dan perilaku manusia yang selalu mencari alasan sehingga menolak informasi-informasi dari Allah menyebabkan munculnya berbagai penyakit seperti AIDS, penyakit kelamin, dan sebagainya.

Laporan diskusi dialog komunitas LGBT Nasional Indonesia menyatakan bahwa perilaku seksual dan identitas gender telah dikenal di wilayah nusantara sejak dahulu, identitas homoseksual baru muncul di kota-kota besar pada awal abad XX. Pada akhir tahun 1960 gerakan LGBT mulai berkembang melalui kegiatan pengorgansasian yang dilakukan oleh kelompok wanita transgender, atau waria. Mobilisasi pria gay dan wanita lesbian terjadi pada tahun 1980-an, melalui penggunaan media cetak dan pembentukan kelompok-kelompok kecil di seluruh Indonesia. Mobilisasi ini semakin mendapatkan dorongan dengan maraknya HIV pada tahun 1990-an, termasuk pembentukan berbagai organisasi di lebih banyak lokasi. 
Setelah peristiwa dramatis tahun 1998 yang membawa perubahan mendasar pada sistem politik dan pemerintahan Indonesia, gerakan LGBT berkembang lebih besar dan luas dengan pengorganisasian yang lebih kuat di tingkat nasional, program yang mendapatkan pendanaan secara formal, serta penggunaan wacana HAM untuk melakukan advokasi perubahan kebijakan di tingkat nasional (Laporan LGBT Nasional Indonesia - Hidup Sebagai LGBT di Asia, 2013).

Fenomena LGBT tumbuh dengan subur di Indonesia karena kran kebebasan semakin terbuka, sehingga kampanyekampanye terbuka dapat dilakukan dengan memainkan isu Hak Azazi Manusia. Dengan adanya keterbukaan ini komunitas LGBT merapatkan barisan untuk mempengaruhi pemuda-pemuda yang belum tersentuh dengan berbagai modus dan yang lebih penting lagi adalah keberadaan para aktivis yang dianggap pahlawan untuk memperjuangkan eksistensi LGBT.

Di Barat, isu moral yang terus menggoncang dan memicu kontroversi hebat hingga saat ini adalah masalah homoseksualitas, bahkan kalangan Gereja Kristen direpotkan dalam penentuan batas-batas moral mengenai homoseksualitas. Homoseksualitas telah dicap sebagai praktek kotor dan maksiat oleh agama, namun kemudian berubah menjadi praktek yang manusiawi dan harus dihormati sebagai bagian dari penghormatan Hak Azazi Manusia (Adian Husaini, 2005: 4).

Homoseksualitas adalah istilah yang mengacu pada interaksi seksual atau romantis antara pribadi yang berjenis kelamin sama. Homoseks adalah kata sifat yang digunakan untuk hubungan intim atau hubungan seksual di antara orang yang berjenis kelamin sama, bisa sebagai gay atau lesbian. Istilah gay adalah istilah tertentu yang digunakan untuk merujuk kepada pria homoseks. Sedangkan lesbian adalah suatu istilah tertentu yang digunakan untuk merujuk kepada wanita homoseks.

Islam adalah agama yang beradab dan selalu memberikan perhatian penuh kepada umatnya terutama dalam masalah yang tidak lazim menurut Islam. Lesbian dalam kitab figh disebut dengan as-sahaq atau al-musahaqah berarti hubungan seksual yang terjadi di antara sesama wanita. Rasulullah bersabda (Al-Baihaqi, 1994: 233):

عن أبي موسى قال قال رسول الله صلى الله عليه و سلم : إذا أتى الرجل الرجل فهما زانيان وإذا أتت المرأة المرأة

$$
\text { فهما زانيتان }
$$

Dari Abi Musa, Rasulullah bersabda: apabila ada laki-laki mendatangi (berhubungan intim) dengan laki-laki maka keduanya telah berzina, dan apabila wanita mendatangi wanita maka keduanya telah berzina (HR. Al-Baihaqi).

Sedangkan gay dikenal dengan istilah liwat yang merupakan peninggalan dari Nabi Luth As. Nama lain dari gay ini adalah sexual inversion, contrary sexual feeling atau urning.

Penelitian ini bertujuan untuk mengetahui posisi hukum LGBT ditinjau dari pandangan Hukum Islam dan aplikasi hukum tersebut dalam konteks Indonesia. 


\section{METODE PENELITIAN}

Metode penelitian dalam penelitian ini menggunakan metode kualitatif dengan menggunakan pendekatan deskriptif-analitis yang bertujuan untuk memberikan gambaran tentang hukum yang berkaitan dengan LGBT dan menganalisis permasalahan yang dikemukakan antara dua gejala atau lebih. Prinsip dasar penelitian kualitatif adalah penelitian yang dimulai dari persoalan mengapa, bagaimana, apa, di mana, dan bilamana tentang suatu fenomena-fenomena atau gejala-gejala sosial yang terjadi di lapangan. Penelitian kualitatif yang baik juga menyediakan pemerhatian deskriptif yang sistematik dan berdasarkan konteks, karena pendekatan ini memberikan ruang bagi peneliti untuk belajar tentang suatu sistem serta hubungan semua aktivitas dalam sistem tersebut yang dapat dilihat secara total dan bukan secara sebagian saja (Iskandar, 2008: 188).

Yang menjadi sumber primer dalam penelitian ini adalah kitab figh empat mazhab, sedangkan sumber sekunder adalah laporan-laporan yang berkaitan dengan $L G B T$.

\section{PEMBAHASAN}

\section{Tinjauan Pustaka}

Hampir seluruh sistem sosial berbagai negara di dunia menolak adanya homoseksual. 74 negara dari 204 negara yang ada di dunia menganggap bahwa perilaku homoseksual adalah ilegal. Negara-negara tersebut berasal dari kultur Islam dan merupakan negaranegara komunis atau bekas koloni Inggris (Colin Spencer, 2004: 469).
Teori tentang homoseksualitas yang berkembang saat ini pada dasarnya dibagi menjadi dua golongan: esensialis dan konstruksionis. Esensialisme berpendapat bahwa homeseksual berbeda dengan heteroseksual sejak lahir, hasil dari proses biologi dan perkembangan. Teori ini menyatakan bahwa homoseksualitas adalah abnormalitas perkembangan yang membawa perdebatan bahwa homoseksualitas adalah penyakit. Sebaliknya konstruksionis berpendapat bahwa homoseksualitas adalah sebuah peran sosial yang telah berkembang secara berbeda dalam budaya dan waktu berbeda, dan hal ini menyebabkan bahwa homoseksual dan heteroseksual tidak ada perbedaan secara lahiriah (Janell L. Caroll, 2005: 284).

Di antara beberapa teori yang menyebabkan terjadi homoseksualitas adalah:

1. Faktor herediter berupa ketidakseimbangan hormon-hormon seks.

2. Pengaruh lingkungan yang tidak baik atau tidak menguntungkan bagi perkembangan kematangan seksual normal.

3. Seseorang selalu mencari kepuasan relasi homoseks, karena ia pernah menghayati pengalaman homoseksual yang menggairahkan pada masa remaja.

4. Seorang anak laki-laki pernah mengalami traumatis dengan ibunya, sehingga timbul kebencian atau antipati terhadap ibunya dan semua wanita, lalu muncul dorongan homoseksual (Kartono Kartini, 1989: 248).

Deviasi tersering lebih lazim terjadi pada masa ramaja dan pria (homoseksualitas fakultatif). Ditemukan dalam banyak mamalia tidak matang serta 
dalam kebudayaan manusia yang terkadang tidak membangkitkan celaan dan hukuman. Mungkin satu dari tiga pria semasa hidupnya pernah mendapatkan pengalaman homoseksual, tetapi hanya sekitar empat persen yang benar-benar homoseksual. Faktor mempunyai makna yang meragukan. Penelitian hormon memperlihatkan tidak ada perbedaan dalam kadar testoteron, walaupun diduga ada defiensi androgen perinatal. Dalam beberapa kasus terlihat ada faktor psikogenik mis. Terganggunya hubungan orang tua-anak atau adanya godaan dan pengalaman traumatik semasa kanakkanak (I.M Ingram, dkk., 1993: 86).

Masalah LGBT belakangan ini telah memasuki tahap serius, hal ini terbukti dengan dikeluarkannya fatwa MUI yang menyerukan berbagai hukuman mulai dari hukuman cambuk hingga hukuman mati bagi pelaku homo seksual pada Maret 2015. Menurut Hasanuddin AF, fatwa ini dikeluarkan karena penyimpangan seksual semakin meningkat bahkan telah menyusup ke sekolah-sekolah. Sedangkan menurut Asrorun Ni'am Sholeh, sodomi lebih buruk daripada perzinaan dan seks di luar nikah dan dihukum dengan hukuman lebih keras (Nahimunkar.com, https://www.nahimunkar.com, akses pada 31 Mei 2016).

\section{Hasil}

\section{LGBT dan Faktor-faktor yang Mempengaruhi}

Orientasi seksual digambarkan sebagai objek impuls seksual seseorang: heteroseksual (jenis kelamin berlawanan, homoseksual (jenis kelamin sama) atau biseksual (kedua jenis kelamin). Istilah homoseksual kerap digunakan untuk menggambarkan perilaku jelas seseorang, orientasi seksual, dan rasa identitas pribadi atau sosial. Hawkin menjelaskan bahwa istilah gay atau lesbian merupakan identitas diri atau identitas sosial. Sedangkan Soekanto menjelaskan homoseksual adalah seseorang yang cenderung mengutamakan orang yang sejenis kelaminnya sebagai mitra seksual (Soerjono Soekanto, 2004: 381).

Homoseksual merupakan sebutan secara umum kepada orang yang bersangkutan atau homoseks. Sebutan tersebut hanya digunakan sebagai suatu tanda pengenal pembeda dengan heteroseksual dan biseks. Istilah homoseksual hanya digunakan pada hubungan sejenis saja baik laki-laki maupun perempuan, istilah ini masih banyak disalahartikan sebagai sebagai hubungan gay, namun istilah gay hanya digunakan untuk pria homoseks, sedangkan lesbian digunakan untuk wanita homoseks. Yang termasuk dalam kategori homoseks adalah transgender dan biseksual, baik female to male maupun male to female.

Dalam teori Born that Why yang diusulkan oleh Le Vay tahun 1996. Menurutnya banyak faktor yang bertanggung jawab atas keberadaan orientasi homoseksual dalam masyarakat. Teori ini juga menyatakan bahwa tempramental dan lingkungan adalah penyebab utama terjadinya homoseksual. Tempramental terdiri dari kombinasi gen, jaringan otak, dan lingkungan hormon prenatal (sebelum lahir). Lingkungan merupakan penyebab homoseksual yang terbentuk dari orang tua, teman sebaya, dan pengalaman.

Gen + Brain Writing + Lingkungan Prenatal = Tempramental

Orang tua + teman sebaya + pengalaman $=$ Lingkungan 
Oleh sebab itu, tempramental + lingkungan = orientasi homoseksual

LGBT dalam pandangan psikologi dibagi menjadi dua bagian, yaitu yang menerima atas orientasi seksualnya dan yang tidak menerima namun tidak mempunyai daya untuk mengatasinya sehingga ia merasa terganggu. Di Indonesia perilaku LGBT dikategorikan sebagai gangguan jiwa yang terangkum dalam PPDGJ (Panduan Pedoman Diagnostik Gangguan Jiwa. Akan tetapi pada tahun 1983 LGBT telah dikeluarkan dari PPDGJ. Dengan demikian perilaku tersebut sudah tidak tergolong lagi dalam bentuk gangguan jiwa tetapi hanya merupakan salah satu bentuk orientasi seksual semata (Dede Oetomo, 2001: 24).

Posisi antara seseorang homoseksual sebagai penyimpangan seksual atau sebagai perilaku alamiah dan normal selalu diperdebatkan hingga sekarang, karena hal ini menyangkut usaha para aktivis dan pelaku LGBT agar kegiatan tersebut diterima dan dilegalkan. Kegiatan ini menimbulkan hasil yang memuaskan bagi mereka, karena pada tahun 1974 APA (American Psychiatric Association) menghapus homoseksual dari salah satu kelainan jiwa.

Tom Boellstorff menganalisis bahwa dalam konteks Indonesia istilah gay dan lesbi mulai populer pada tahun 1970 hingga 1980. Istilah ini tidak dipelajari dari orang tua, tetangga, dan guru-guru agama Islam melainkan dari media massa, termasuk kolom-kolom gosip di majalah dan koran. Hal ini sesuai dengan pendapat Anderson (1983) tentang peranan penting media massa sebagai sarana penciptaan sentimen nasionalisme kolektif di era modern. Ini disebabkan sebagian besar gay dan lesbi di Indonesia tidak bisa berbahasa Inggris serta tidak bepergian ke negeri-negeri Barat (Tom Boeollstorff, 2006:3).

\section{Komentar al-Qur'an mengenai Fenomena LGBT}

Islam menginginkan pernikahan antar lawan jenis (laki-laki dan perempuan) bukan semata-mata hanya memenuhi hasrat biologis namun sebagai ikatan suci untuk menciptakan ketenangan hidup dengan membentuk keluarga sakinah dan mengembangkan keturunan umat manusia yang bermartabat.

Dalam Alquran peristiwa homoseksual ini menjadi perhatian pening, hal ini terbukti dengan adanya beberapa ayat yang berbicara mengenai hal ini, seperti Q.S. alA'raf: 80, Q.S. An-Naml: 54, Q.S. Asyu'ara: 165, dan Q.S. Hud: 77-82.

Allah Swt berfiman dalam surat AlA'raf 80:

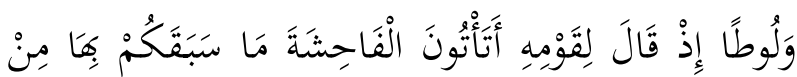

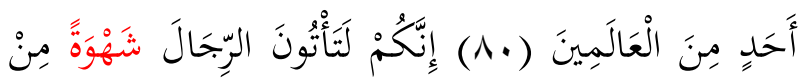

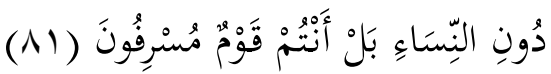

Dan ingatlah ketika Luth berkata kepada kaumnya: "Mengapa kalian melakukan perbuatan kotor yang belum pernah dilakukan oleh seorang pun di dunia. Sesungguhnya kalian mendatangi laki-laki untuk melepaskan nafsu kepada mereka bukan kepada perempuan. Bahkan kalian semua adalah orang yang telah melampaui batas. (Q.S. al-A'Raf [7]: 80-81)

Pada ayat di atas dijelaskan bahwa Nabi Luth mempertanyakan kepada kaumnya ketika melakukan kedurhakaan yang besar, apakah kamu melakukan 
fahisyah, yaitu melakukan pekerjaan yang buruk (homoseksual) yang belum pernah dilakukan oleh seseorangpun di alam ini. Perbuatan demikian merupakan bentuk kedurhakaan mereka terhadap Allah Swt. Nabi Luth dalam ayat ini sedikit berbeda dengan Nabi-nabi sebelumnya. Beliau tidak berpesan tentang tauhid, hal ini tidak berarti beliau tidak mengajak kepada tauhid, namun satu masalah yang sangat jelek harus beliau selesaikan bersama pelurusan akidah. Orang yang melakukan homoseksual hanya mengharapkan kenikmatan jasmani yang menjijikkan.

Dalam tafsir al-Manar dijelaskan bahwa Nabi Luth diutus Allah untuk memperbaiki akidah serta akhlak kaumnya yang tinggal di negeri Sadum, Adma', Sabubim dan Bala' di Tepi Laut Mati. Nabi Luth menetap di kota yang paling besar dari lima kota tersebut, yaitu Sadum. Sadum mengalami kehancuran moral, kaum laki-laki lebih senang bersyahwat kepada sesama jenisnya yang lebih muda dan tidak bersyahwat kepada wanita (Rasyid Ridha, 1950: 509).

Perbuatan homoseksual tidak pernah dibenarkan dalam keadaan apapun. Pembunuhan dapat dibenarkan apabila untuk membela diri atau menjatuhkan sanksi hukum, begitu juga hubungan seks dengan lawan jenis dibolehkan oleh agama kecuali berzina, apabila terjadi dalam keadaan syubhat, maka dapat ditoleransi dengan batas-batas tertentu.

Dalam surat an-Naml: 54 Allah Swt menjelaskan:

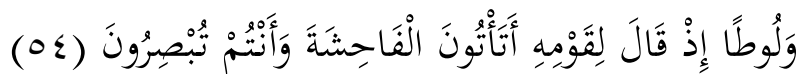

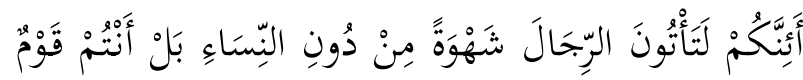

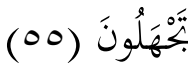

Dan (ingatlah kisah) Luth, ketika Dia berkata kepada kaumnya: "Mengapa kamu mengerjakan fahisyah sedang kamu memperlihatkannya. Mengapa kamu mendatangi laki-laki untuk memuaskan nafsumu, bukan mendatangi wanita? Sebenarnya kamu adalah kaum yang tidak mengetahui. (Q.S. an-Naml [27]: 54-55)

Dari ayat di atas Nabi Muhammad Saw diingatkan dengan perilaku umat Nabi Luth bahwa apakah kamu tidak berakal atau tidak malu mengerjakan perbuatan fahisyah, yaitu sikap yang sangat buruk dalam pandangan akal dan adat kebiasaan manusia. Kamu menyaksikan manusia bahkan hewan melampiaskan hawa nafsu kepada lawan jenisnya, lakilaki dengan perempuan dan jantan dengan betina. Dampak yang dihasilkan dari perbuatan ini adalah penyakit yang belum ditemukan obatnya (M. Quraish Shihab, 2002: 241).

Pelajaran yang dapat diambil dari ayat ini adalah keadaan istri Nabi Nuh dan Luth ada dua orang wanita yang mengkhianati suami mereka. Pengkhianatan ini bukan hanya menyeleweng atau berzina akan tetapi tidak mempercayai kenabian mereka dan pura-pura menampakkan keimanan padahal keduanya kafir. As-Sya'rawi menyatakan jangan kalian menganggap isteri kedua Nabi tersebut angkuh terhadap suami mereka, sebenarnya keduanya tunduk terhadap kepemimpinan suami mereka, namun persoalan iman dan kufur adalah kebebasan individu dan Nabi tidak memaksakan kehendak mereka terhadap isterinya.

Adanya beberapa orang yang melakukan perbuatan liwat pada kaum Nabi Luth memberikan pengaruh yang kuat kepada masyarakat yang lain pada waktu itu. Lingkungan memberikan pengaruh 
yang kuat terhadap perilaku yang jelek tersebut, seperti dijelaskan oleh Paul Cameron:

1. Sub-kultul homoseksual yang tampak dan diterima secara sosial akan mengundang rasa ingin tahu dan menumbuhkan rasa ingin mencoba.

2. Pendidikan yang pro-homoseksual (hal ini terjadi apabila para pendukung homoseksual berhasil masuk ke kurikulum sekolah).

3. Toleransi sosial dan hukum terhadap perilaku homoseksual.

4. Adanya figur yang secara terbuka berperilaku homoseksual.

5. Penggambaran bahwa homoseksualitas adalah perilaku normal dan dapat diterima.

\section{Analisis Hukum Islam terhadap Perilaku LGBT}

Islam mengakui bahwa manusia memiliki hasrat untuk melangsungkan hubungan seks, terutama terhadap lawan jenis. Islam mengatur hal ini dalam sebuah lembaga yang dinamakan dengan perkawinan. Melalui perkawinan, fitrah manusia dapat terpelihara dengan baik, sebab perkawinan mengatur hubungan seks antara pria dan wanita. Dengan adanya perkawinan yang disyariatkan, maka Islam melarang segala bentuk hubungan seks di luar perkawinan. Sebab akan berdampak kepada kekacauan hubungan biologis dan bisa merusak garis keturunan dan menyebabkan permusuhan dan pembunuhan (Sudiman, 2002: 91).

Pembicaraan mengenai homoseksual selama ini selalu berujung pada hukuman bagi para pelakunya, karena dalil keharamannya menurut ahli figh telah ditetapkan oleh Alquran seperti yang ditetapkan pada umat Nabi Luth. Oleh karena itu para imam mazhab kecuali Hanafi menetapkan hukuman rajam hingga mati bagi pelaku homoseksual. Sedangkan Hanafi berpandangan hal ini termasuk maksiat yang tidak ditetapkan secara pasti oleh Allah, maka dihukum $t a^{\prime} z i r$ (pemberian pelajaran), karena bukan bagian dari zina (Ibn al-Qayyim alJauziyah, 1996: 168).

Menurut Sayid Sabiq liwat atau homoseks merupakan perbuatan yang dilarang oleh syara' dan merupakan jarimah yang lebih keji daripada zina. Liwat merupakan perbuatan yang bertentangan dengan akhlak dan fitrah manusia dan berbahaya bagi manusia yang melakukannya (Sayyid Sabiq, 1981: 361). Para ulama figh berbeda pendapat tentang hukuman homoseks, di antaranya adalah:

1. Dibunuh secara mutlak.

2. Dihad seperti had zina. Bila pelakunya jejaka maka didera dan rajam apabila di telah menikah.

3. Dikenakan hukum ta'zir. (Sayyid Sabiq, 1981: 432).

Mengenai larangan perilaku homoseksual, Rasulullah Saw bersabda:

$$
\begin{aligned}
& \text { عَنْ عِكِرِمَةَ عَنْ ابْنِ عَبَّاسِ قَالَ: قَالَ رَسُوْلُ الله ص.م: }
\end{aligned}
$$

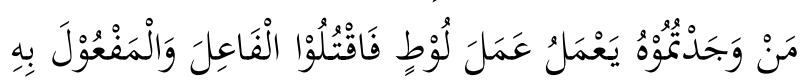

$$
\begin{aligned}
& \text { (رواه الخمسة الا النسائي) }
\end{aligned}
$$

Dari Ikrimah, dari Ibn Abbas, Rasulullah bersabda: "Barang siapa yang kamu dapati melakukan perbuatan kaum Nabi Luth (homoseksual) maka bunuhlah si pelaku dan yang dikerjainya (objeknya)". (HR. Lima ahli Hadis kecuali an-Nasa'i) 
Ibn al-Qayyim menjelaskan bahwa kerusakan yang diakibatkan oleh perilaku homoseksual sangat besar. Mengenai kedudukan hukum antara homoseksual dan zina terdapat tiga pendapat, antara lain (Ibn al-Qayyim al-Jawziyah, t.th.: 241):

1. Abu Bakar al-Shiddiq, Ali ibn Abi Thalib, Khalid ibn Walid, Abdullah ibn Zubair, Abdullah ibn Abbas, Jabir ibn Zaid, Abdullah ibn Ma'mar, Az-Zuhri, Rabi'h ibn Abi Abdirrahman, Malik, Ishaq ibn Rawaih, Ahmad, dan AsSyafi'i menyatakan hukum liwat lebih berat daripada zina dan hukumnya adalah dibunuh.

2. Atha' ibn Rabah, Hasan al-Basri, Sa'id ibn Musayyab, Ibrahim An-Nakh'i, Qatadah dan Al-Auza'i menyatakan hukumnya sama dengan zina

3. Al-Hakam dan Abu Hanifah menyatakan hukumnya adalah selain zina, yaitu $t a^{\prime} z i r$.

Yusuf Al-Qaradhawi berpandangan bahwa perilaku homoseksual bertentangan dengan fitrah manusia dan merusak sifat kelaki-lakian dan merampas hak-hak perempuan. Perbuatan ini dapat merusak tatanan masyarakat dan manusia tidak lagi menghiraukan etika, kebaikan dan perasaan (Yusuf al-Qaradhawi, 1997: 151).

\section{PENUTUP}

\section{Kesimpulan}

Seluruh agama telah menetapkan ketentuan pernikahan yang sah sebagai penjaga sakralitas hubungan suami isteri yang telah terjamin legalitasnya. Allah Swt telah melarang seluruh perilaku yang menyimpang karena menyimpan beberapa hikmah yang apabila direnungkan sangat banyak manfaatnya bagi manusia. Namun, sikap dan perilaku manusia yang selalu mencari alasan sehingga menolak informasiinformasi dari Allah menyebabkan munculnya berbagai penyakit seperti AIDS, penyakit kelamin, dan sebagainya.

Perbuatan liwat atau homoseks merupakan perbuatan yang dilarang oleh syara' dan merupakan jarimah yang lebih keji daripada zina. Liwat merupakan perbuatan yang bertentangan dengan akhlak dan fitrah manusia dan berbahaya bagi manusia yang melakukannya. Para ulama figh berbeda pendapat tentang hukuman homoseks, di antaranya adalah:

1. Dibunuh secara mutlak.

2. Dihad seperti had zina. Bila pelakunya jejaka maka didera dan rajam apabila di telah menikah.

3. Dikenakan hukum $t a^{\prime} z i r$.

\section{DAFTAR KEPUSTAKAAN}

Al-Baihaqi. 1994. Sunan al-Kubra. Makkah: Maktabah Dar al-Bazz,

Boeollstorff, Tom. 2006. “Gay dan Lesbian Indonesia serta Gagasan Nasionalisme" terj. Iwan Meulia, Social Analisys.

Caroll, Janell L.. 2005. Sexuality Now: Embracing Diversity. Belmont, CA:Wadsworth/Thomson.

Himawan, Anang Harris. 2007. Bukan Salah Tuhan Mengazab: Ketika Perzinahan menjadi Berhala Kehidupan. Solo: Tiga Serangkai.

https://www.nahimunkar.com diakses pada Selasa, 31 Mei 2016

Husaini, Adian. 2005. Wajah Peradaban Barat: Dari Hegemoni Kristen ke 
Dominasi Sekuler-Liberal. Jakarta: Gema Insani Press.

I.M Ingram, dkk., 1993. Catatan Kuliah Psikiatri Terj. Petrus Andrianto (Jakarta: Penerbit Buku Kedokteran EGC).

Iskandar. 2008. Metodologi Penelitian Pendidikan dan Sosial (Kualitatif $\mathcal{E}$ Kuantitatif). Jakarta: Gang Persada Press.

Kartini, Kartono. 1989. Psikologi Abnormal dan Abnormalitas Seksual. Bandung: Mandar Maju.

Laporan LGBT Nasional Indonesia Hidup Sebagai LGBT di Asia. 2013
Oetomo, Dede. 2001. Memberi Suara pada Yang Bisu. Yogyakarta: Galang Press.

Shihab, M. Quraish. 2002. Tafsir al-Misbah: Pesan, Kesan, dan Keserasian al-Qur'an. Jakarta: Lentera Hati.

Soekanto, Soerjono. 2004. Sosiologi Keluarga: tentang Ihwal Keluarga, Remaja dan Anak. Jakarta: PT. Rineka Cipta.

Spencer, Colin. 2004. Sejarah Homoseksualitas. Yogyakarta: Kreasi Wacana. 